\title{
Erratum to: Switching of mesodermal and endodermal properties in hTERT-modified and expanded fetal human pancreatic progenitor cells
}

\author{
Kang Cheng ${ }^{1}$, Antonia Follenzi ${ }^{2}$, Manju Surana ${ }^{3}$, Norman Fleischer ${ }^{3}$ and Sanjeev Gupta ${ }^{4}$
}

\section{Erratum}

After publication of our article [1], errors were noticed in the composition of data in Figures threeC, fiveD and sixA (Figs. 1c, 2d and 3a here respectively). The data from original gels were incorrectly compiled or modified by the first author, Dr. K. Cheng, which was not noticed by the other authors.

In figure threeC (Fig. 1c here) the original gels for the following genes were incorrectly represented - GATA-2, GATA-6, ISL-1, Pdx1, CGA, GK, TGF- $\alpha$, TGF- $\beta 1$, TGF- $\beta 2$, TGF- $\beta 2 R$, and GAPDH. Expression of these genes in mature islets was verified by additional studies.

In figure fiveD (Fig. 2d here) some of the lanes were cut out of the composition, and others were mislabeled.

In figure sixA (Fig. 3a here) the published figure was erroneously composed with incorrect or distorted images.

The correct figures are provided here. These errors do not affect the results or conclusions of our study.

Please note the change in corresponding author email address since the publication of our original article.

\footnotetext{
*Correspondence: sanjeev.gupta@einstein.yu.edu

${ }^{4}$ Hepatology Division, Department of Medicine, Cancer Research Center,

Diabetes Research Center, Center for Human Embryonic Stem Cell Research,

Marion Bessin Liver Research Center, Ruth L. and David S. Gottesman

Institute for Stem Cell and Regenerative Medicine Research, and Institute for

Clinical and Translational Research, Albert Einstein College of Medicine,

Ullmann Bldg., Rm 625, 1300 Morris Park Avenue, Bronx, NY 10461, USA

Full list of author information is available at the end of the article
} 

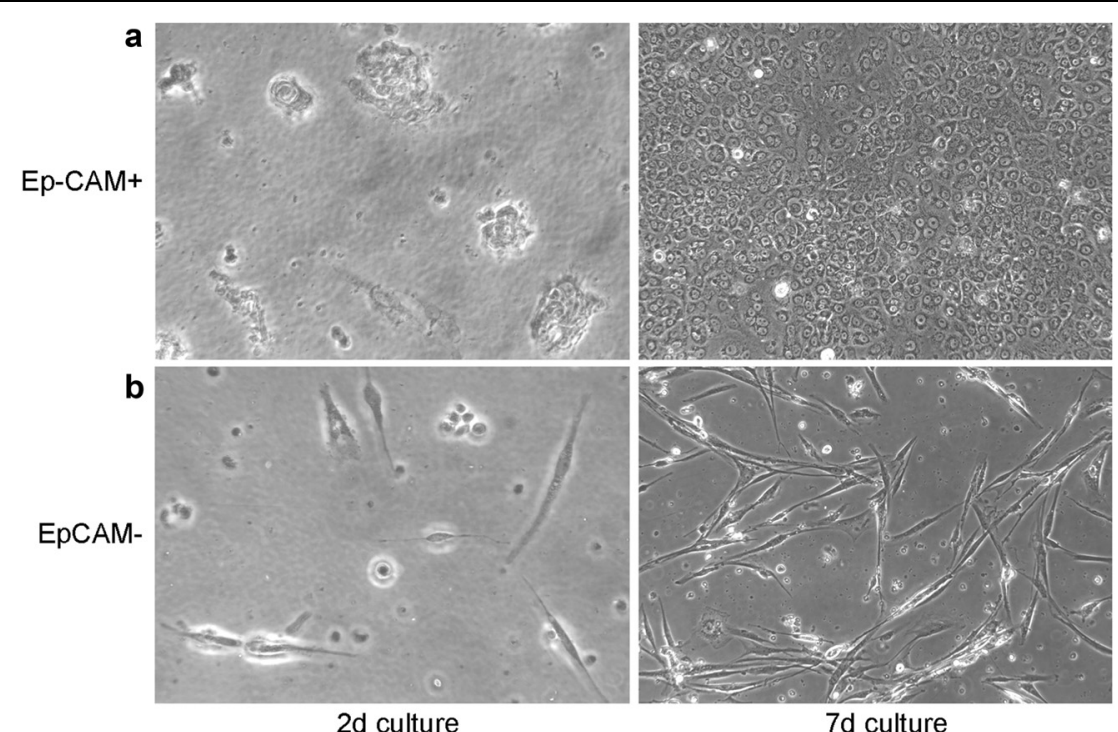

C
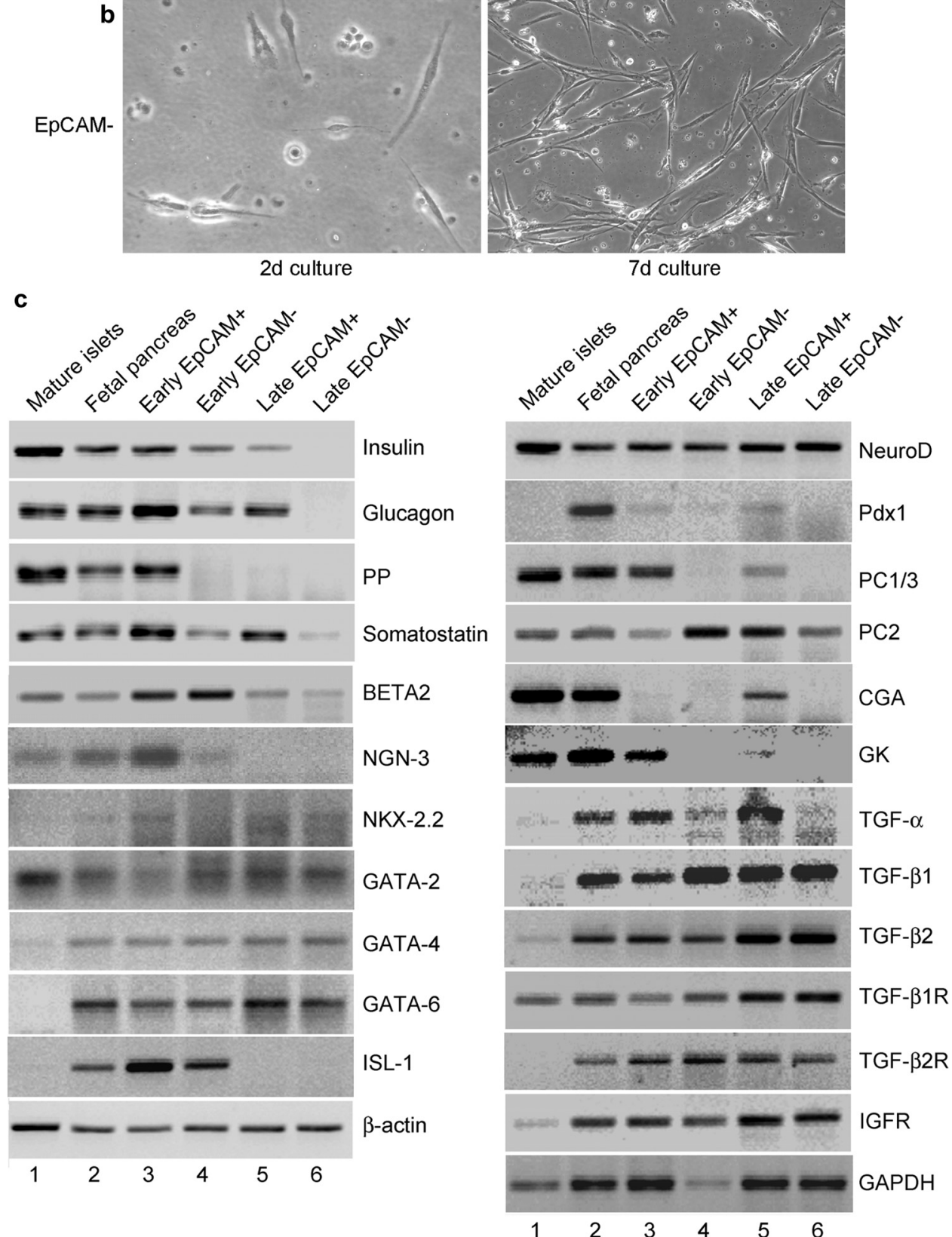

$7 \mathrm{~d}$ culture

Fig. 1 Initial characterization of fetal pancreatic cells. a and $\mathbf{b}$ show morphology of cells in culture after $2 \mathrm{~d}$ and $7 \mathrm{~d}$. Note epithelial morphology of EpCAM-positive cells. c shows RT-PCR for genes as indicated. Lanes 1 to 6 show results from mature human pancreatic islets, intact fetal pancreas, cells after early term culture ( 1 to 2 d) or longer culture (10 to 14 d). For comparisons, $\beta$-actin and glyceraldehyde phosphate dehydrogenase (GAPDH) genes were included 


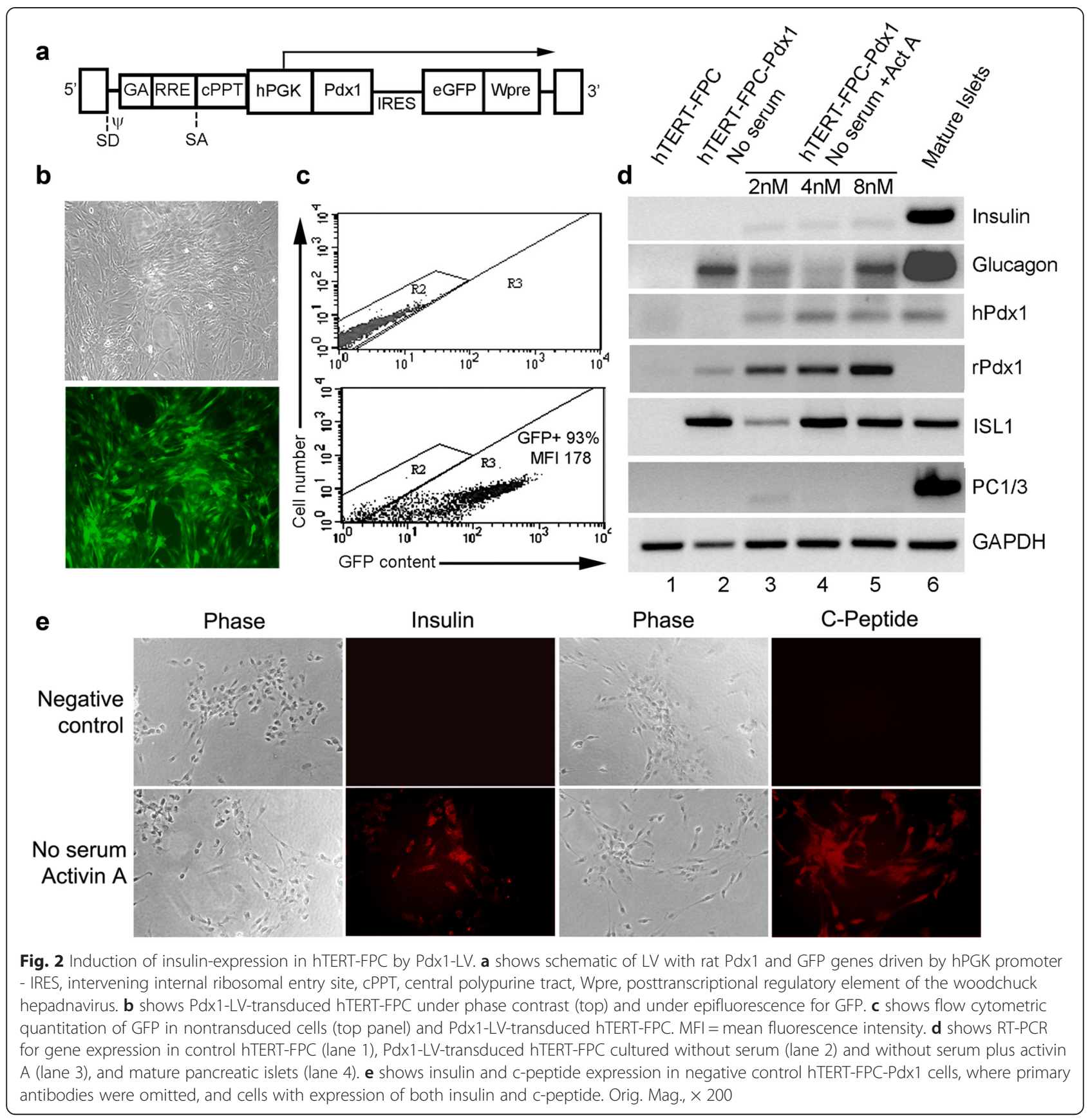




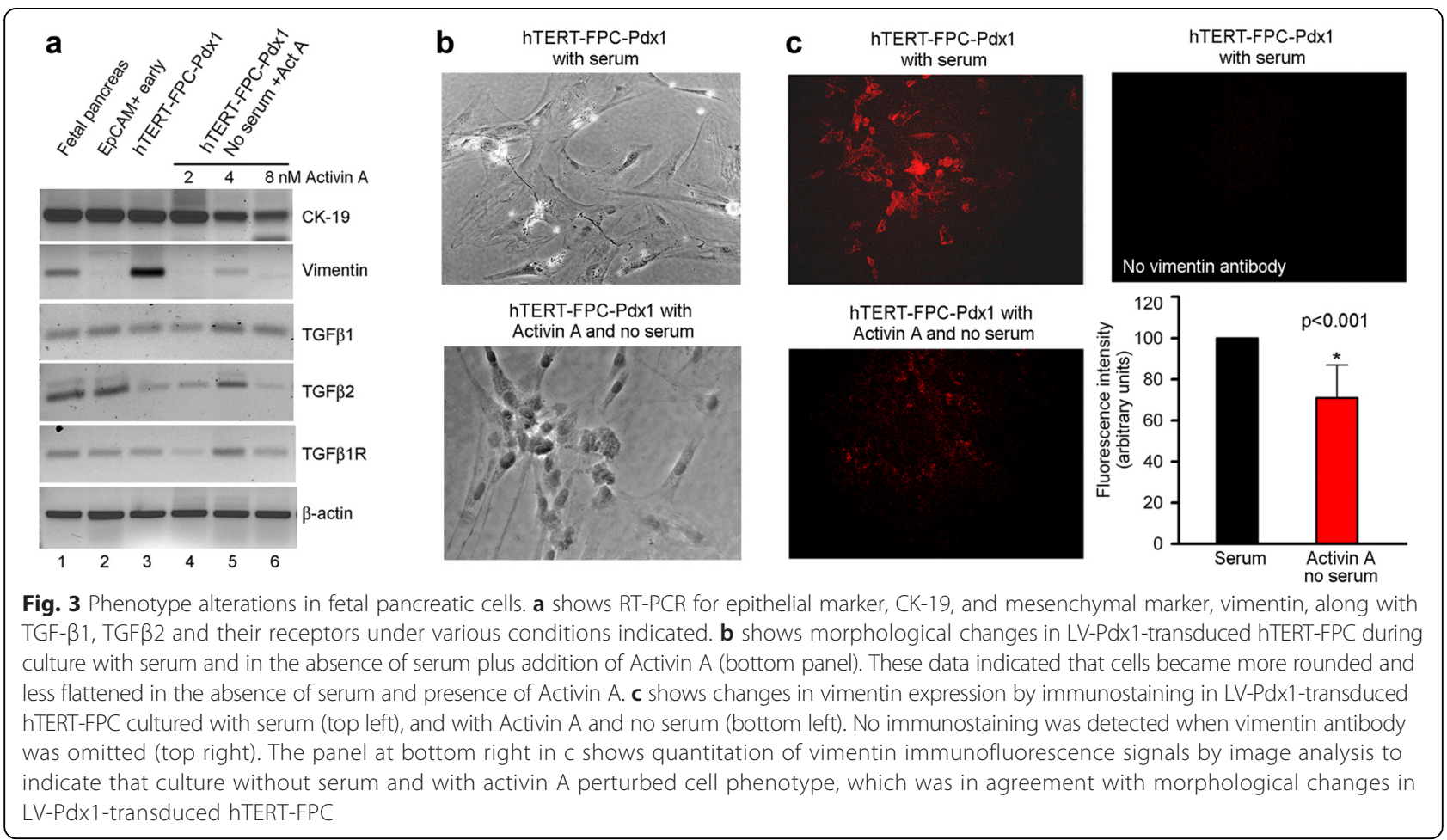

\section{Author details}

${ }^{1}$ Hepatology Division, Department of Medicine, Albert Einstein College of Medicine, Ullmann Bldg., Rm 625, 1300 Morris Park Avenue, Bronx, NY 10461, USA. ${ }^{2}$ Department of Pathology, Albert Einstein College of Medicine, Ullmann Bldg., Rm 625, 1300 Morris Park Avenue, Bronx, NY 10461, USA.

${ }^{3}$ Endocrinology Division, Department of Medicine, Diabetes Research Center, Albert Einstein College of Medicine, Forchheimer Bldg., Rm 505, 1300 Morris Park Avenue, Bronx, NY 10461, USA. ${ }^{4}$ Hepatology Division, Department of Medicine, Cancer Research Center, Diabetes Research Center, Center for Human Embryonic Stem Cell Research, Marion Bessin Liver Research Center, Ruth L. and David S. Gottesman Institute for Stem Cell and Regenerative Medicine Research, and Institute for Clinical and Translational Research, Albert Einstein College of Medicine, Ullmann Bldg., Rm 625, 1300 Morris Park Avenue, Bronx, NY 10461, USA.

Received: 1 September 2015 Revised: 1 September 2015 Accepted: 1 September 2015 Published online: 30 September 2015

\section{Reference}

1. Cheng K, Follenzi A, Surana M, Fleischer N, Gupta S. Switching of mesodermal and endodermal properties in hTERT-modified and expanded fetal human pancreatic progenitor cells. Stem Cell Res Ther. 2010;1:6.

\section{Submit your next manuscript to BioMed Central and take full advantage of:}

- Convenient online submission

- Thorough peer review

- No space constraints or color figure charges

- Immediate publication on acceptance

- Inclusion in PubMed, CAS, Scopus and Google Scholar

- Research which is freely available for redistribution 